\title{
Influence of Chlorosulfonation on the Surface Mechanical Properties of Lamellar Polyethylene
}

\author{
J. Martinez-Salazar, D. R. Rueda, M. E. Cagiao, E. López-Cabarcos* and F. J. Baltá Calleja \\ Instituto de Estructura de la Materia, C.S.I.C. Serrano 119, Madrid-6, Spain
}

\begin{abstract}
SUMMARY
The hardening of lamellar polyethylene (PE) as a consequence of a controlled chlorosulfonation treatment has been studied using the microindentation technique. The hardness of the polymer turns out to be a linear func tion of the density of treated PE. The rate of increase is larger for samples with higher crystallinity. This increase is related to the hardening of crystal lame liae due to the surface attachment of electron dense groups. The latter impede the slippage of crystals and substantially reduce the rate of creep of the material under the contact pressure applied.
\end{abstract}

In a recent study (MARTINEZ-SALAZAR et al 1983) the characteristic morphological details of IDPE after controlled chlorosulfonation treatment were investigated. A salient feature of this study was the large weight increase $(\sim 100 \%)$ of the samples for sufficiently long periods of treatment time (50-100h). After reaction the groups fixed at the chains are predominantly $\mathrm{HSO}_{3}$ (KANIG 1973) though additional oxidative groups have ${ }^{3}$ been also detected (HRADIL and STAMBERG 1971). An important result is that the thickness of the lamellar structure assessed by electron microscopy (EM), does not change with chlorosulfonation time. However, after long treatment times $(\sim 100 \mathrm{~h})$, when a saturation of electron-dense groups takes place within the amorphous layers, a reduction of the lateral dimensions of the lamellae is detected.

In the present study we set out to examine to what extent the penetration of the electron dense groups within the amorphous layer of the lamellar structure can affect the surface mechanical properties of the polymer. We have previously shown that surface hardness (MH) is a remarkably sensitive property to morphological changes undergone by polymers. Specifically 
in isotropic $\mathrm{PE}, \mathrm{MH}$ depends on crystal thickness, unit cell packing, crystallinity etc. (BALTA CALLEJA et al 1981). The thicker are the crystals, the larger is the cohesion energy opposing a greater resistance to plastic deformation. The interlamellar non crystalline component contributes, on the other hand, to a reduction of the hardness value. The object of this study is, thus to investigate the influence of the selective chemical attack within the interlamellar component on the resistance to the local plastic deformation of the modified polymer.

The molecular weight, branching content and crystallinity of the investigated samples are given in

TABLE I

\begin{tabular}{|l|c|c|c|}
\hline \multicolumn{1}{|c|}{ Sample } & $\mathrm{M}_{\mathrm{W}} \times 10^{3}$ & $\varepsilon\left(\frac{8}{8}\right)$ & $\alpha\left(\frac{q}{8}\right)$ \\
\hline Hostalen GC & 50 & 0.28 & 73 \\
Lupolen KR 1032 & 53 & 2.53 & 45 \\
Epolene C 10 & 21 & 4.77 & 35 \\
\hline
\end{tabular}

Densities were measured by the gradient column and the flotation methods using a mixture of $\mathrm{Cl}_{4} \mathrm{C}$ and Toluene. Further experimental details on the morphology of the samples and the acid treatment can be found elsewhere (J. MART INEZ-SALAZAR et al 1983). Hardness measurements were performed with a Leitz tester using a square pyramid indenter $(100 \mu \mathrm{m}$ height). The hardness value was calculated from the projected area of the residual indentation according to: $M H=k p / d^{2}$ (GPa), where $d$ is the length of the impression diagonal, $\mathrm{p}$ is the con tact load applied and $k$ is a geometrical factor equal to $18.18 \times 10^{3}$. Hardness is, hence, taken as indicative of the irreversible deformation processes which characterize the material. Loads of $5 \times 10^{-2} \mathrm{~kg}$ were used to obtain sufficient indentation areas which minimize the inherent inhomogenities of the degraded material.

Fig. 1 illustrates the striking increase of hardness as a function of treatment time for various sam ples. The initial hardness value $(t=0)$ is known to be an increasing function of lamellar thickness, and, hence, of crystallinity (BALTA CALLEJA 1976). The polymer has been, further, visualized as a composite consisting of hard (crystalline) and weak (amorphous) elements whose overall hardness responds to $\mathrm{H}=\alpha \mathrm{H}_{\mathrm{C}}+(1-\alpha) \mathrm{H}_{\mathrm{a}}$ (BALTA CALLEJA et al 1981), where $\mathrm{H}_{\mathrm{C}}$ and $\mathrm{H}_{\mathrm{a}}$ are the hardness values of the crystals and amorphous layers respectively. Fig. 1 also indicates that for a given treatment temperature, the sample with 


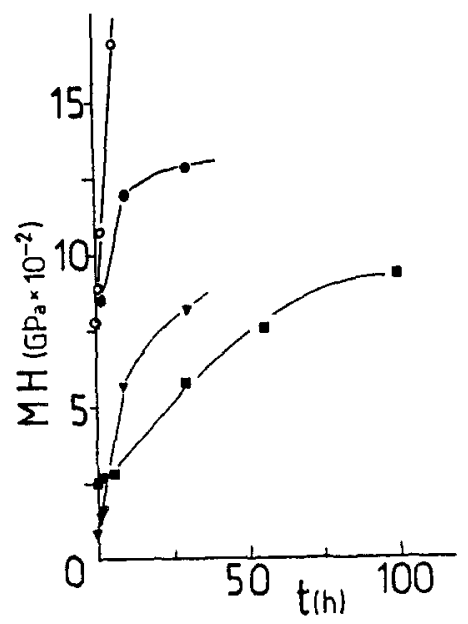

Fig. 1. Surface hardness of polyethylene with different crystallinities $(\alpha=35 \%$ ( $), \alpha=45 \%$ ( $)$ and $\alpha=73 \%(0,0))$ as a function of chlorosulfonation time. Treatment temperatures: $\mathrm{T}=20^{\circ} \mathrm{C}(\boldsymbol{\nabla}, \boldsymbol{\square})$, $\mathrm{T}=45^{\circ} \mathrm{C}$ (O) and $\mathrm{T}=60^{\circ} \mathrm{C}(\mathrm{O})$

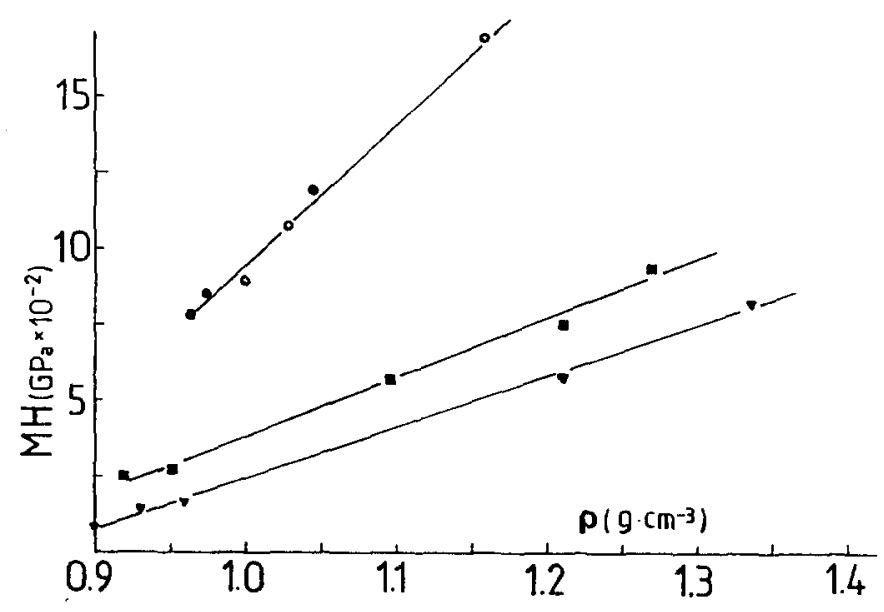

Fig. 2. Microhardness increase of chlorosulfonated polyethylene vs. density for the three crystallinities investigated $(\alpha=35 \%(\nabla)$, $\alpha=45 \%$ (a) and $\alpha=73 \%(0,0))$. 
a larger amorphous content $(\alpha=35 \%)$ shows a MH increase much faster with $t$ than the material with a lower disordered content $(\alpha \sim 45 \%)$. Conversely, for a given crystallinity $\mathrm{MH}$ increases more rapidly with increasing treatment temperature. Comparison of the $\mathrm{MH}$ data with the weight increase $(\triangle P)$ of the polymer as a function of treatment time previously reported (MARTINEZ-SALAZAR 1983) shows the evident parallelisms between these two quantities with a common initial increase and a final leveling off tendency. It seems, hence, plausible to correlate the spectacular $\mathrm{MH}$ increase with the gradual penetration of heavy groups reacting at chain sites within the amorphous layer. Now the question rises as to whether the hardness increase is related to the hardening of the interlamellar regions, or else to the hardening of crystals themselves due to a crystal surface attachment of heavy groups. For this purpose we have inspected the hardness of treated samples as a function of density. Earlier results (MARTINEZ-SALAZAR and BALTA CALLEJA 1983) emphasize the fact that hardness is indeed a quantity dependent on density $\rho$. Fig. 2 illustrates the clear linear increase of $\mathrm{MH}$ with $\rho$ for the three samples under study. These data show that the higher is the crystallinity value (i.e. larger crystals) the larger is the rate of hardness increase with increasing density due to heavy group penetration. This result unambiguously favours the second alternative proposed; namely that of a crystal hardening owing to selective attachment of $\mathrm{HSO}_{3}$ groups on the crystal surface. A similar hardening effect has been reported (BALTA 1976) for PE treated with fuming nitric acid. In this case, it was suggested that the $\mathrm{MH}_{\mathrm{H}}$ increase was due to the higher cohesion energy caused by the formation of dicarboxylic end groups at the crystal surface capable to form hydrogen bonds. The detected increase in the melting temperature and enthalpy of the material after chlorosulfonation (For Hostalen GC, $T_{m}$ changes from $130.6^{\circ} \mathrm{C}$ to $137.7^{\circ} \mathrm{C}$ and $\Delta \mathrm{H}$ from $230 \mathrm{Jg}^{-1}$ to $263 \mathrm{Jg}^{-1}$; For Lupolen KR $1032 \mathrm{~T}_{\mathrm{m}}$ increases from $110.5^{\circ} \mathrm{C}$ to $116.3^{\circ} \mathrm{C}$ and $\Delta \mathrm{H}$ from $126 \mathrm{Jg}^{-1}$ to $217 \mathrm{Jg}^{-1}$ ) supports the concept of crystals with larger cohesion energies due to surface group attachment. TEM observations, specially on the LDPE sample (MARTINEZ-SALAZAR et al 1983) substantiate the preferential attack at the surface of the lamellae showing well defined contrast lines on the crystal surfaces. Finally, the study of $\mathrm{MH}$ as a function of loading time (Fig. 3) further illuminates these aspects. Indeed, the final hardness value can be written as $\mathrm{MH}=\mathrm{MH}_{0.1} \mathrm{t}^{-\mathrm{K}}$ where $\mathrm{MH}_{0.1}$ is the value at $t=0.1 \mathrm{~min}$ and the constant $K$ provides a measure of the rate of creep of the material under the indenter. It is known that $K$ depends on crystal perfection (BALTA 1983). The results of Fig. 3 indicate that $k$ decreases notoriously after the acid treatment. This suggests that after 
chemical modification at the surface, with eventual hydrogen bond formation, the crystal slip under the applied contact pressure proceeds at a much slower rate.

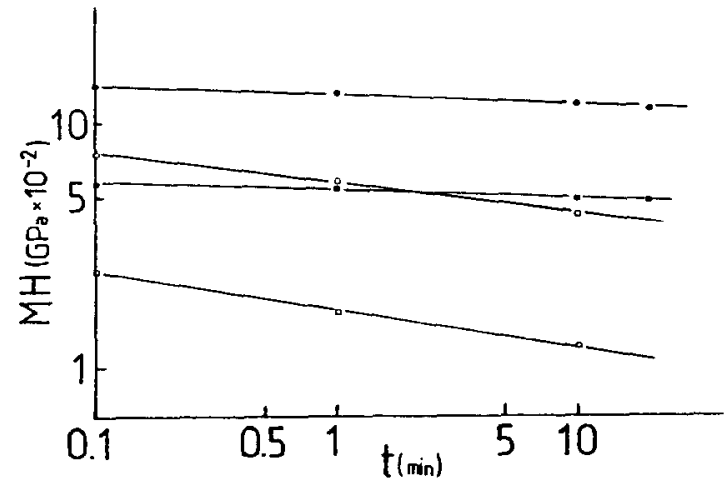

Fig. 3. Microhardness as a function of loading time for PE before $(\alpha=73$ 응 (O) and $\alpha=45 \%$ (口)) and after $30 \mathrm{~h}$ (solid symbols) of chlorosulfonation treatment

In conclusion, the chlorosulfonation mechanism in PE can be conveniently followed by the microhardness technique. This study suggests that chlorosulfonation involves a preferential hardening of the crystallites. These show a higher thermodynamic stability after treatment and a concurrent linear increase of hardness with increasing density of modified samples due to oxidative group attachment at the crystal surface. The latter causes a substantially lower creep rate of the polymer during the test.

ACKNOWLEDGMENT.- Grateful acknowledgment is due to CAICYT, Madrid for the generous support of this investigation.

\section{REFERENCES}

BALTA CALLEJA, F.J., Colloid and Polymer Sci. 254,258 (1976)

BALTA CALLEJA, F.J., MARTINEZ-SALAZAR, J., CACKOVIC, H. LOBODA-CACKOVIC, I., J. Mater. Sci. 16, 739 (1981)

BALTA CALLEJA, F.J. (unpublished results, 1983)

HRADIL, J. and STAMBERG, J., Collection Czechoslov. Commum. vol. 37,3868 (1972)

KANIG, V.G., Kolloid Z.u.z. Polymere, 251, 782 (1973) MARTINEZ-SALAZAR, J., KELLER, A., CAGI $\overline{A O}$, M.E., RUEDA, D.R. , BALTA CALLEJA, F.J. Colloid \& Polym.Sci261, 412 (1983) MARTINEZ-SALAZAR, J. , BALTA CALLEJA, F.J., J. Mater. Sci., 18, 1077 (1983) 